\title{
Central Banks Quasi-Fiscal Policies and Inflation
}

Seok Gil Park 


\title{
IMF Working Paper
}

Fiscal Affairs Department

\section{Central Banks Quasi-Fiscal Policies and Inflation \\ Prepared by Seok Gil Park ${ }^{1}$}

Authorized for distribution by Abdelhak Senhadji

January 2012

\begin{abstract}
Although central banks have recently taken unconventional policy actions to try to shore up macroeconomic and financial stability, little theory is available to assess the consequences of such measures. This paper offers a theoretical model with which such policies can be analyzed. In particular, the paper shows that in the absence of the fiscal authorities' full backing of the central bank's balance sheet, strange things can happen. For instance, an exit from quantitative easing could be inflationary and central banks cannot successfully unwind inflated balance sheets. Therefore, the fiscal authorities' full backing of the monetary authorities' quasi-fiscal operations is a pre-condition for effective monetary policy.
\end{abstract}

JEL Classification Numbers: E31; E58; E63

Keywords: Central bank's balance sheet; Fiscal theory of price level; Quasi-fiscal policy Author's E-Mail Address:spark@imf.org

\section{This Working Paper should not be reported as representing the views of the IMF.} The views expressed in this Working Paper are those of the author(s) and do not necessarily represent those of the IMF or IMF policy. Working Papers describe research in progress by the author(s) and are published to elicit comments and to further debate.

\footnotetext{
${ }^{1}$ I am grateful to Carlo Cottarelli, Daehaeng Kim, Eric Leeper, Joon Park, Abdelhak Senhadji, Lars Svensson, Fabian Valencia, Todd Walker, Tack Yun and the seminar participants at the Federal Reserve Board of Governors, IMF's Fiscal Affairs Department, Indiana University, the $10^{\text {th }}$ World Congress of the Econometric Society, the 2009 Midwest Macroeconomics Meeting, and Sveriges Riksbank for their helpful comments. All remaining errors are mine.
} 


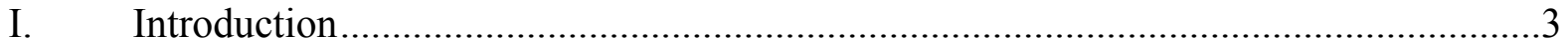

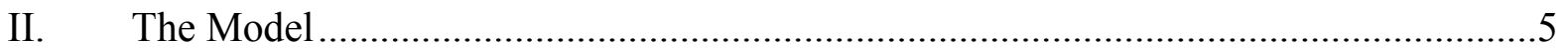

A. Private Agent's Optimization..............................................................................

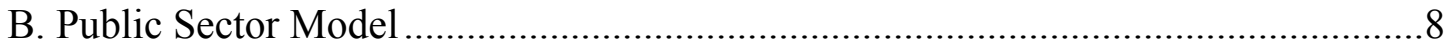

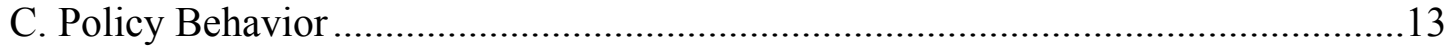

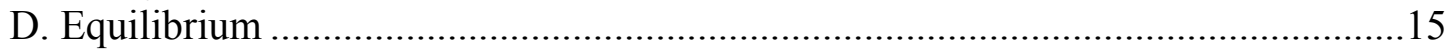

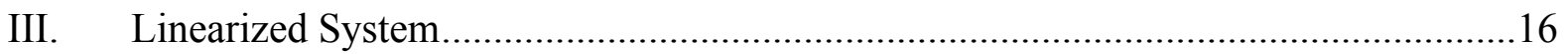

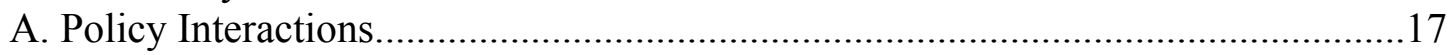

B. Equilibrium in the Active Quasi-Fiscal Policy Regime ......................................19

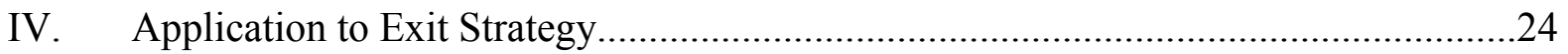

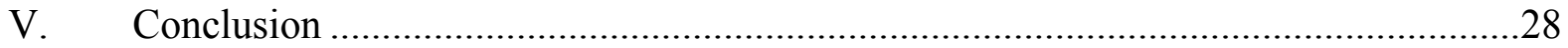

\section{Appendixes}

I. Part of the Proof for Proposition 1 ....................................................................29

II. Solution of the Dynamic System in Section III .................................................... 31

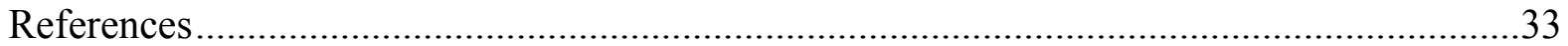




\section{INTRODUCTION}

Recently, central banks implemented unconventional operations by accumulating risky assets in an attempt to mitigate the financial turmoil that began in 2008 and the Euro zone fiscal crises. The operations altered the central banks' balance sheet in both size and substance, and the magnitude of these operations was significant. ${ }^{2}$ These operations can be referred to as a 'quasi-fiscal policy' of central banks because they do not conform to traditional monetary policy, which is used to stabilize inflation by controlling the policy interest rate. ${ }^{3}$ Instead of being innate to central banks, most of these activities could be implemented by fiscal authorities. In this paper, a quasi-fiscal policy is defined as any policy action that affects the central banks' balance sheets, with the exception of the traditional monetary policy mentioned above. For example, since credit easing operations alter the composition of the central banks' asset accounts, they are considered quasi-fiscal policies. If losses are incurred from the central bank's assets and the fiscal authorities decide not to compensate these losses, then the fiscal authorities' decision is also a quasi-fiscal policy because it decreases the central banks' capital account.

Some have worried that the quasi-fiscal policies of the central bank may undermine its independence and ability to stabilize inflation (Sims, 2003; and Goodfriend, 2011). In this regard, Goodfriend (2011) proposed accord principles between the central banks and fiscal authorities that will insulate the central banks from quasi-fiscal policy shocks. Also, an empirical study by Klüh and Stella (2008) showed that financially weak central banks were ineffective in stabilizing inflation. However, little economic theory is available to explain how and when the central banks' quasi-fiscal policy affects inflation and imposes restriction on monetary policy. The issue can be particularly crucial for central banks without sound fiscal support, such as the European Central Bank. This paper proposes a simple dynamic stochastic general equilibrium (DSGE) model in order to address the following questions: (i) Do quasi-fiscal policies and the central banks' balance sheets affect inflation? and (ii) Do the central banks' balance sheets have implications for policy interactions between the central banks and fiscal authorities?

The model predicts that the central banks' balance sheet shocks affect inflation through private agents' (households') portfolio adjustment when the fiscal authorities do not financially support central banks. That is, in that particular policy regime, the price level is determined by a ratio between the nominal and real value of the central bank's net liability. For example, suppose that a central bank with a negative capital suffers additional losses from long-term bond holdings while the central bank tries to increase short-term interest rate in response to inflationary pressure. As the real value of holding the central bank's net liability falls below the equilibrium with the negative return shock, then the private agent

\footnotetext{
${ }^{2}$ For example, the Federal Reserve System's asset account was $\$ 894$ billion at the end of 2007, but increased to $\$ 2,266$ billion at the end of 2008 .

${ }^{3}$ Mackenzie and Stella (1996) defined a quasi-fiscal activity as "an operation or measure carried out by a central bank ... with an effect that can, in principle, be duplicated by budgetary measures ... and that has or may have an impact on the financial operations of the central bank" (p. 17).
} 
tries to decrease holdings of the central bank's liability (nominal money balance) and increase consumption. In the end, the general price level increases, and the central bank passively increases nominal money supply in order to satisfy real money balance demand. Paradoxically, the hike in the policy rate (deflationary monetary policy) induces inflation in this case. In other words, the central bank is confined to a situation where it cannot play an active role in stabilizing inflation. Since fiscal support of the central bank's balance sheet precludes such type of equilibrium, therefore, the fiscal authority's back-up is a pre-condition for effective monetary policy when the central bank is engaged in the other policy role such as maintaining financial stability.

Sargent and Wallace (1981), Leeper (1991) and Sims (1994) connected monetary and fiscal policy by showing that one policy may impose restrictions on the other policy, and that the two policies should interact in a coherent way in order to deliver a unique equilibrium. In this conventional approach to policy interaction, the budget constraints of the central banks and fiscal authorities are consolidated into a single equation. In other words, conventional models implicitly assume that the fiscal authorities acknowledge the central banks' liabilities and assets as their own liabilities and assets, and that the central banks' losses are automatically compensated by the fiscal authorities. Owing to these assumptions, in conventional models the budget constraint of the central banks does not impose restrictions on the equilibrium.

However, questions can be raised about this conventional assumption. Stella and Lönnberg (2008) surveyed 135 central banks and discovered that laws did not always guarantee the fiscal authorities' responsibility for the central banks' liabilities, and that the fiscal authorities are not always prompt in recapitalizing the central banks. In this regard, this paper relaxes the conventional assumption by elaborating on the institutional details which state that the central banks' flow budget constraint is separate from the fiscal authorities' flow budget constraint. In addition, this paper's public sector model includes the fiscal authorities' transfer rule for recapitalizing the central banks, and the transfer rule is the key quasi-fiscal policy in the benchmark model.

Furthermore, this paper departs from conventional models by assuming that the real values of the central banks' and fiscal authorities' liabilities have finite upper bounds, which are the expected present values of their future earnings. Owing to this assumption, the peculiar equilibria, where the fiscal authorities and central banks can run a Ponzi scheme on each other and the real value of the central banks' capital grows (or shrinks) infinitely, are excluded from this paper. By utilizing this assumption and the institutional details of the flow budget constraints, we show that the intertemporal equilibrium condition from the central banks' budget constraint (the central banks' net liability valuation formula) restrict equilibrium inflation in a certain policy regime.

In the abovementioned policy regime, quasi-fiscal policy is 'active,' while monetary and fiscal policies are 'passive. ${ }^{3}$ The active quasi-fiscal policy means that the fiscal authorities

\footnotetext{
${ }^{4}$ Active and passive policies are defined by Leeper (1991). That is, an active policy is not constrained by the private agent's optimization (thus equilibrium conditions), states of the economy, and other policies.
} 
do not stabilize the central banks' real capital and do not increase the fund transfer to the central banks when losses are incurred. As described in the previous example, monetary and fiscal policies are passively adjusted in order to satisfy the other equilibrium conditions, thus equilibrium inflation is uniquely determined by the central banks' net liability valuation formula in this regime. In this regard, this paper is an extension of the Fiscal Theory of Price Level (FTPL) such as Leeper (1991). The model in this paper includes two intertemporal equilibrium conditions (from the public sector's separated flow budget constraints) and three policy instruments (monetary, fiscal, and quasi-fiscal), whereas one intertemporal equilibrium condition (from the public sector's consolidated flow budget constraint) and two policy instruments (monetary and fiscal) exist in the conventional FTPL.

A few studies have been completed that shed light on the effects of concerns over the central banks' balance sheets. Jeanne and Svensson (2007) showed that if the central banks suffer losses when their capital falls under a fixed level, then the central banks' commitment to escape from the liquidity trap is more credible. Sims (2003) showed that the central banks' balance sheet concerns might undermine the central banks' abilities to prevent inflation. Berriel and Bhattarai (2009) showed that the optimal monetary policy is significantly different when the central bank's budget constraint is separate from the fiscal authorities' budget constraint. Specifically, as the central banks place higher effective weight on inflation in the loss function, the variation in inflation decreases.

One of the differences between this paper and previous literature on the central banks' balance sheets is that a new type of equilibrium exists even if the policy interest rate does not depend upon the status of the central banks' balance sheets. For example, in Jeanne and Svensson (2007) and Berriel and Bhattarai (2009), the central banks' loss function includes a deviation of the central banks' real capital. In these cases, the central banks' monetary policy behavior may be restricted by the balance sheet concerns. However, the monetary policy behavior in this paper follows a simple Taylor rule. In other words, the central bank, in this paper, will not generate seigniorage in response to its balance sheet concerns.

The remainder of this paper is organized as follows. In Section II, we build the model for the rational-expectations general equilibrium in exact nonlinear forms. In Section III, the equilibrium conditions are linearized around the deterministic steady state in order to derive analytic solutions. In addition, we explain the equilibrium in the active quasi-fiscal policy regime in this section. The benchmark model is extended to include the exit strategy in Section IV, and Section V concludes the paper.

\section{THE MODEL}

\section{A. Private Agent's Optimization}

This model is a closed economy dynamic stochastic general equilibrium (DSGE) model with

money in the utility function. Output is given by the exogenous endowment process $\left\{y_{t}\right\}_{t=0}^{\infty}$ for simplicity. The representative agent solves the following problem: 


$$
\max _{\left\{c_{t}, M_{t}, B_{t}^{4}\right\}_{t=0}^{\infty}} E_{0}\left[\sum_{t=0}^{\infty} \beta^{t}\left\{u\left(c_{t}\right)+v\left(\frac{M_{t}}{P_{t}}\right)\right]\right\}, 0<\beta<1,
$$

s.t.

$$
\begin{gathered}
c_{t}+\frac{M_{t}}{P_{t}}+\frac{B_{t}^{A}}{P_{t}} \leq y_{t}-\tau_{t}+\frac{M_{t-1}}{P_{t}}+\frac{\left(1+i_{t-1}\right) B_{t-1}^{A}}{P_{t}}, c_{t}, M_{t} \geq 0, \forall t \geq 0, \\
M_{-1}+\left(1+i_{-1}\right) B_{-1}^{A}>0,
\end{gathered}
$$

where $u(\cdot)$ is the utility function for consumption, $v(\cdot)$ is the utility function for the real money balance, $c_{t}$ is the single consumption goods, $\tau_{t}$ is the lump-sum tax, $M_{t}$ is the nominal money balance, the agent holds $B_{t}^{A}$ units of the government's risk-free one-period nominal bonds, $P_{t}$ is the price level, $E_{t}[\cdot]$ is the expectation based on the information available in period $t, i_{t}$ is the risk-free net nominal interest rate and the initial level of financial wealth $M_{-1}+\left(1+i_{-1}\right) B_{-1}^{A}$ is given exogenously. The first order condition yields the following Euler equations:

$$
\begin{gathered}
\frac{v^{\prime}\left(m_{t}\right)}{u^{\prime}\left(c_{t}\right)}+E_{t}\left[X_{t, t+1} \frac{P_{t}}{P_{t+1}}\right]=1, \\
\frac{1}{R_{t}}=E_{t}\left[X_{t, t+1} \frac{P_{t}}{P_{t+1}}\right], \\
X_{t, t+1} \equiv \beta \frac{u^{\prime}\left(c_{t+1}\right)}{u^{\prime}\left(c_{t}\right)}, R_{t} \equiv 1+i_{t},
\end{gathered}
$$

where $u^{\prime}(\cdot)$ and $v^{\prime}(\cdot)$ refer to the first order derivative of $u(\cdot)$ and $v(\cdot), m_{t}$ is the real money balance $M_{t} / P_{t}, X_{t, t+1}$ is the real pricing kernel (or the discount factor) between period $t$ and $t+1$ and $R_{t}$ is the risk-free gross nominal interest rate. Equation (2) governs the money demand of the agent and Equation (3) leads to the Fisher equation.

In order to ensure the existence of the agent's unique optimal choice, the transversality condition should be assumed. Specifically, the agent cannot borrow a greater amount than the finite present value of her future income. This optimal condition is expressed in the following condition: 


$$
w_{t}^{A} \equiv \frac{M_{t-1}+R_{t-1} B_{t-1}^{A}}{P_{t}} \geq-\sum_{T=t}^{\infty} E_{t}\left[X_{t, T}\left(y_{T}-\tau_{T}\right)\right]>-\infty, \forall t
$$

where $w_{t}^{A}$ is the agent's real financial wealth at period $t$ and $X_{t, T} \equiv \prod_{s=t}^{T-1} X_{s, s+1}$. In the optimal path, the flow and intertemporal budget constraint are satisfied by equality and it can be shown that (1) and (4) lead to the transversality condition for the agent as follows:

$$
\lim _{T \rightarrow \infty} E_{t}\left[X_{t, T} w_{T}^{A}\right]=0, \forall t
$$

If the limit term in Equation (5) is strictly positive, then the agent accumulates an additional financial asset that rolls over permanently. Obviously, this scenario is not optimal for the agent because the agent sacrifices her consumption without any compensation. On the other hand, if the limit term in Equation (5) is negative, then the agent is allowed to borrow an additional unit of debt and roll it over permanently. This scenario is ruled out by the NoPonzi scheme assumption, which can be seen in Condition (4).

The market clearing conditions are imposed for the general equilibrium. Specifically, the goods market, the nominal money and the government bonds market should be cleared as follows:

$$
\begin{gathered}
c_{t}=y_{t,} \\
M_{t}^{s}=M_{t}, \\
B_{t}^{s}=B_{t}^{A}+B_{t}^{C}, \forall t,
\end{gathered}
$$

where $M_{t}^{s}$ is the nominal money supply, $B_{t}^{s}$ is the government nominal bonds supply and $B_{t}^{C}$ is the central bank's demand for the government nominal bonds. ${ }^{5}$ Then, after imposing market clearing conditions, the Euler equations turn into the following equilibrium conditions under the standard assumptions on preferences:

$$
\begin{gathered}
\frac{M_{t}^{s}}{P_{t}}=f^{*}\left(\frac{i_{t}}{1+i_{t}} u^{\prime}\left(y_{t}\right)\right) \equiv f\left(y_{t}, i_{t}\right), \\
\frac{1}{R_{t}}=E_{t}\left[\beta \frac{u^{\prime}\left(y_{t+1}\right)}{u^{\prime}\left(y_{t}\right)} \frac{P_{t}}{P_{t+1}}\right], \forall t,
\end{gathered}
$$

\footnotetext{
${ }^{5}$ Determination of $B_{t}^{C}$ will be explained in the next section.
} 
where $f^{*}(\cdot)$ refers to the inverse function of $v^{\prime}(\cdot)$. Equation (9) states that the supply of the real money balance should be equal to the agent's real money demand, and Equation (10) is the Fisher equation. In order to completely define the rational-expectations general equilibrium, the policy behavior of the fiscal authority and the central bank should be specified. Section II.B and II.C will explain the public sector model and the policy behavior.

\section{B. Public Sector Model}

Goodfriend (2011) argued that the quasi-fiscal operations ${ }^{6}$ of the central bank may undermine monetary policy's credibility and independence, thus an 'accord' between the central bank and the fiscal authority is needed in order to ensure the central bank's ability to stabilize the economy. In his proposal, the accord principle is to minimize the central bank's exposure to balance sheet risks and to guarantee the central bank's credit to the private sector by the fiscal agent. Then the question is what would happen in the general equilibrium model if such an accord does not exist? In order to tackle the issue, this section elaborates a public sector model by incorporating the details of central banking.

The first aspect of institutional details is an isolation of the central bank's balance sheet from the fiscal authority. Owing to this factual aspect, the flow budget constraint of the consolidated government in conventional models is divided into two equations: one for the central bank and one for the fiscal authority. The second aspect consists of assumptions about the agent's expectations in regard to the two public institutions' liabilities. Similar to the NoPonzi scheme assumption in conventional models, the second aspect assumptions turns the separated flow budget constraints of the two institutions into separated intertemporal equilibrium conditions (IECs). These separated intertemporal equilibrium conditions impose an additional restriction on the equilibrium and is a main deviation from conventional models.

\section{Separation of flow budget constraint}

The consolidated government's flow budget constraint in conventional models is as follows:

$$
\underset{\Delta \text { asset }}{0}=\underbrace{\frac{B_{t}^{A}-B_{t-1}^{A}}{P_{t}}+\frac{M_{t}-M_{t-1}}{P_{t}}}_{\text {هliability }}+\underbrace{s_{t}-\frac{i_{t-1} B_{t-1}^{A}}{P_{t}}}_{\Delta \text { capital }} .
$$

where the fiscal surplus $s_{t}$ is the lump-sum tax $\tau_{t}$ less the fiscal authority expenditure in units of real goods. ${ }^{7}$ The liability includes both the fiscal authority's debts issued to households and monetary liability (nominal money) as the balance sheets of two institutions are consolidated in this case.

\footnotetext{
${ }^{6}$ Goodfriend (2011) defined 'credit policy' as adjustments of asset portfolio composition of the central bank, such as "lending to particular borrowers with proceeds from the sale of treasuries." The credit policy, in his definition, can be rendered as quasi-fiscal policy as it affects the central bank's balance sheet.

${ }^{7}$ The government spending is assumed to be zero for all time periods. No result relies on this assumption.
} 
If the public sector model reflects the fact that the central bank's balance sheet is isolated from the balance sheet of fiscal authority, then the consolidated constraint (11) should be divided into two constraints as follows:

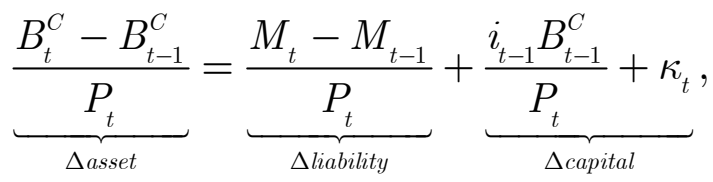

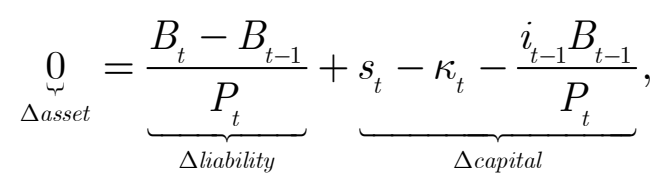

where $B_{t}$ refers to the fiscal authority's total debt sold to households and to the central bank $\left(B_{t}=B_{t}^{C}+B_{t}^{A}\right.$ ), the central bank accumulates the fiscal authority's bond holdings $\left(B_{t}^{C}\right)$ as an instrument for open market operations, and $\kappa_{t}$ refers to the transfer from the fiscal authority to the central bank in the real goods unit. ${ }^{8}$ Note that the central bank's budget constraint (12) omits the central bank's various accounts such as risky loans to the financial sector, which are accrued by quasi-fiscal activities, for simplicity.

\section{Separation of intertemporal equilibrium condition}

The central bank's separated budget constraint (12) is an accounting identity which does not necessarily affect equilibrium. However, an extra set of assumptions, which governs the private agent's expectations on the two public institutions' relationship, turns the identity into an equilibrium condition. The argument is similar to the conventional models' cases, such as Woodford (2001), where the consolidated government budget constraint (11) can be solved forward to derive the unified IEC (government debt valuation formula),

$$
\frac{M_{t-1}+R_{t-1} B_{t-1}^{A}}{P_{t}}=\sum_{T=t}^{\infty} E_{t}\left[X_{t, T}\left(\frac{i_{T}}{1+i_{T}} f\left(y_{T}, i_{T}\right)+s_{T}\right)\right] \text {, }
$$

while the equilibrium conditions including the agent's transversality condition (5) are substituted into the constraint.

Proposition 1 states that the unified IEC is separated into two IECs when the agent expects that the central bank and the fiscal authority have bounded real values for their liabilities.

\footnotetext{
${ }^{8}$ Central banks generally submit their net profits to fiscal authorities. In this case, $\kappa_{t}$ is a negative number.
} 
Proposition 1. Suppose the Conditions (15) and (16) are true, $\left|w_{t}^{A}\right|<\infty^{9}$ and $P_{t}, X_{t, T}>0$ for all $t$ and $T>t$,

$$
\begin{gathered}
d_{t}^{C} \equiv \frac{M_{t-1}-R_{t-1} B_{t-1}^{C}}{P_{t}} \leq \sum_{T=t}^{\infty} E_{t}\left[X_{t, T}\left(\frac{i_{T}}{1+i_{T}} f\left(y_{T}, i_{T}\right)+\kappa_{T}\right)\right]<\infty, \\
d_{t}^{F} \equiv \frac{R_{t-1} B_{t-1}^{A}+R_{t-1} B_{t-1}^{C}}{P_{t}} \leq \sum_{T=t}^{\infty} E_{t}\left[X_{t, T}\left(s_{T}-\kappa_{T}\right)\right]<\infty,
\end{gathered}
$$

then the unified IEC (14) is separated into two IECs.

Proof. Note that $d_{t}^{C(F)}$ refers to the real net liability of the central bank (the fiscal authority) at period $t$ and $w_{t}^{A}=d_{t}^{C}+d_{t}^{F}$. Intuitively, the Conditions (15) and (16) mean that the real values of the central bank and the fiscal authority liabilities cannot be greater than the expected present value of the future earnings. Appendix I shows that the following two equations are equivalent to Conditions (15) and (16).

$$
\begin{gathered}
\lim _{T \rightarrow \infty} E_{t}\left[X_{t, T} d_{T}^{C}\right]=0, \\
\lim _{T \rightarrow \infty} E_{t}\left[X_{t, T} d_{T}^{F}\right]=0, \forall t, T>t .
\end{gathered}
$$

Then, the flow budget constraints (12) and (13) are turned into the following IECs by imposing equilibrium conditions ((9) and (10)), and the Conditions ((17) and (18)).

$$
\begin{gathered}
\frac{M_{t-1}-R_{t-1} B_{t-1}^{C}}{P_{t}}=\sum_{T=t}^{\infty} E_{t}\left[X_{t, T}\left(\frac{i_{T}}{1+i_{T}} f\left(y_{T}, i_{T}\right)+\kappa_{T}\right)\right], \\
\frac{R_{t-1} B_{t-1}^{A}+R_{t-1} B_{t-1}^{C}}{P_{t}}=\sum_{T=t}^{\infty} E_{t}\left[X_{t, T}\left(s_{T}-\kappa_{T}\right)\right] .
\end{gathered}
$$

Note that Equation (14) is a sum of Equations (19) and (20).

I refer to the IEC (19) as 'the central bank's net liability valuation formula' because Equation (19) indicates that the real value of the central bank's net liability is equal to the expected

\footnotetext{
${ }^{9}$ Arguably, the real value of government liability $\left(w_{t}^{A}\right)$ is bounded. One can imagine equilibria where the lump-sum tax to output ratio is unbounded. In these equilibria, it may be possible that the government liability to output ratio as well as the lump-sum tax to output ratio are explosive, while the tax to debt ratio remains finite. Canzoneri, Cumby, and Diba's (2001) results showed the Ricardian equivalence under these equilibria. This paper excludes these bizarre equilibria by assumption.
} 
present value of the seigniorage and the transfer earnings from (or payment to) the fiscal authority. ${ }^{10}$ The IEC (20) states that the real value of the fiscal authority's total liability is supported by the current and future fiscal surplus less the transfer to the central bank. It should also be noted that Equations (19) and (20) are not constraints, but are equilibrium conditions from the Euler equations, the agent's optimal conditions, the agent's expectations on the policy institutions and flow budget constraints.

Remark 1. The crux of assumptions (15) and (16) is that the expected present value of the transfers between the two institutions is finite.

In this model, the present values of the seigniorage and fiscal surplus converge to finite values. The convergence of the present value of the seigniorage revenue can be shown by the agent's intertemporal budget constraint, which is Inequality (21).

$$
\sum_{T=t}^{\infty} E_{t}\left[X_{t, T}\left(c_{T}+\frac{i_{T}}{1+i_{T}} \frac{M_{T}}{P_{T}}\right)\right] \leq w_{t}^{A}+\sum_{T=t}^{\infty} E_{t}\left[X_{t, T}\left(y_{T}-\tau_{T}\right)\right]
$$

The right side of Inequality (21) is positive and bounded, which is implied by the agent's NoPonzi scheme assumption (4) and the assumption $\left|w_{t}^{A}\right|<\infty$. Since both consumption and the real balance holding are positive, then the present value of the seigniorage is finite in any equilibrium. The present value of the fiscal surplus should be also finite in the IEC (14). Since the terms other than the present value of transfer are all finite in (15) and (16), the validity of assumptions (15) and (16) hinges on the convergence of the expected present value of the transfers.

A sufficient condition for the convergence of the transfer in the deterministic case is presented in Condition (22). Using the ratio test for the convergence of the infinite series, we get

$$
\limsup \left|X_{T, T+1} \frac{\kappa_{T+1}}{\kappa_{T}}\right|<1,\left|\kappa_{T}\right|<\infty
$$

Condition (22) means that the transfer may grow faster than the real interest rate for only a finite number of time periods. If the transfer grows faster than the real rate for an infinite number of time periods, then the real values of the public institutions' liabilities will grow (or shrink) indefinitely by the flow budget constraints. In this case, the exploding transfer should

\footnotetext{
${ }^{10}$ In order to ensure $P_{t}>0$, it is further assumed that the expected present values of the seigniorage, the fiscal surplus, and the transfer are consistent with the positive price level. For example, in Equation (19), the positive central bank capital ( $M_{t-1}-R_{t-1} B_{t-1}^{C}<0$ ) implies that the expected present value of future transfer from the central bank to the fiscal authority is greater than the seigniorage revenue.
} 
ultimately be financed by the exploding $B^{C}$ since the convergence of the seigniorage and surplus implies that the asymptotic growth rates of the seigniorage and surplus will fall below the real interest rate. The conventional models, without the assumptions (15) and (16), have not excluded this peculiar scenario. In this perspective, the additional set of assumptions (15) and (16) is a lax requirement for the public sector model because the exploding liabilities scenario is hardly imaginable. Indeed, it is observed that restrictions (15) and (16) have been in effect, and that the restrictions become more plausible with the recent trend of the central banks' policy independence. These two rationales are elaborated as follows.

First, the value of the transfers between the governments and central banks (or banknote issuing commercial banks) has been limited in the history of central banking. In the early stage of the central banks' evolution, they were bestowed a charter to issue monetary liability in return for financial favors to the governments. Although the early central banks provided financial services to the governments, the governments usually did not support the early central banks when they were in distress. This feature was revealed by the public's distrust of banknotes in the face of financial crises (Goodhart, 1988, p. 19-20). For example, the failure of the John Law's Banque Royale in France (1720) and the suspension of gold convertibility in England (1797-1819) showed that governments have refused (or been unable) to support the values of the central banks' liabilities. If the governments' transfers to the central banks have infinite present values, then the government should have injected gold (or silver) into the central banks' vaults in order to ensure the convertibility of the banknotes. However, the exact opposite scenario has occurred in history. That is, the governments often suspended convertibility during times of fiscal need. Also, during some occasions, such as during the first world war in Germany, the central banks transferred funds to the governments on a large scale, but such operations came to an end with the occurrence of hyperinflation and regime changes.

Second, as more emphasis is placed on the central banks' policy independence, the assumptions (15) and (16) (or equivalently, (17) and (18)) have become more plausible. That is, Sims (2003) claimed that a trend has occurred to prohibit the compulsory accumulation of the fiscal authority debts by the independent central bank, and that the transactions between the fiscal authority and the independent central bank should be mere by-products of monetary policy. The intuition on Conditions (17) and (18) conforms to the above statements. Specifically, (17) and (18) imply that neither the central bank nor the fiscal authority can run a Ponzi scheme on the other entity. The Ponzi scheme scenario is obviously unacceptable to the central banks which have policy independence where acquisitions of government debts only occur for monetary policy purposes. In other words, the policy independent central bank is expected to reject extreme paths of transfer which violate the Condition (22) and the budgetary independence requirement. In sum, the Conditions (15) and (16) hold ubiquitously for the central banks and are a sensible assumption because the concept is well applicable to both the early central banks as well as to the modern central banks which have policy independence. 


\section{Policy Behavior}

In conventional literature, generally, monetary policy determines the path of the policy interest rate, while fiscal policy decides the path of the fiscal surplus $\left\{s_{t}\right\}$. A description of monetary and fiscal policy behavior is sufficient for determining a unique equilibrium price level in conventional literature because the two terms sufficiently characterize the policy behaviors in (14). However, in this paper, another policy rule must also be established in order to determine the equilibrium as there is an additional unspecified policy variable $\left\{\kappa_{t}\right\}$. This section proposes a rule for the fiscal authority's transfer to the central bank $\left\{\kappa_{t}\right\}$. The rule is referred to as quasi-fiscal policy in the model.

\section{Clarification on quasi-fiscal policy}

Before the policy rules can be specified, we must clarify the concept of quasi-fiscal policy, both in general and in particular for this model. The term quasi-fiscal policy covers a wide range of policy behaviors. As it is already defined in the introduction, quasi-fiscal policy refers to any action, except monetary policy, that affects the central bank's balance sheet. Additional clarifications can be made with respect to the following questions: (i) which public institution decides quasi-fiscal policy? (ii) What are the policy instruments? and (iii) why does this model focus on the transfer between the two institutions as a representative of quasi-fiscal policy?

In regard to the authority in charge of quasi-fiscal policy, both the fiscal authority and the central bank may, in general, decide quasi-fiscal policy. For example, if the central bank decides to provide liquidity to the financial sector, the policy may be the central bank's decision. However, as already noted, the transfer from the fiscal authority to the central bank is also quasi-fiscal policy. If the fiscal authority decides not to transfer funds to the central bank, then the fiscal authority determines the quasi-fiscal policy in this case.

Policy instruments can also vary, based on specific cases. In order to provide liquidity to the financial sector, the central bank can purchase risky assets from the financial sector. In this case, quasi-fiscal policy is implemented by adjusting the central bank's asset account. The sterilized foreign exchange rate intervention is another example in which the central bank's asset account (foreign reserve) is the policy instrument. When a quasi-fiscal activity is aimed at recapitalizing the central bank, the transfer rule from the fiscal authority to the central bank can be used as an instrument.

The benchmark model of this paper excludes all other quasi-fiscal policies and focuses only on the transfer from the fiscal authority to the central bank. This modeling choice is related to the notion of policies' activeness. Leeper (1991) stated that active policy is not constrained by the state of the economy. Specifically, in Leeper (1991), fiscal policy is active when the fiscal authority pays little attention to the level of the real value of government debt when it determines the fiscal policy instrument, the lump-sum tax. In other words, the level of government debt is one of the states of the economy in conventional models. In this paper, the state of the economy includes the level of government debt as well as the central bank's 
capital, which is obvious from the IEC (19) and (20). Then, the modeling choice is to determine which particular quasi-fiscal policy is the most appropriate instrument with which to target the central bank's capital. Targeting the central bank's capital means that the fiscal authority uses the quasi-fiscal policy instrument in order to maintain a certain level of the central bank's capital. Therefore, if the fiscal authority does not target the central bank's capital, the quasi-fiscal policy is active. One of the most direct ways to target the central bank's capital is to transfer funds from the fiscal authority to the central bank because the central banks do not generally impose direct taxes on the agent. Therefore, an appropriate way to model the central bank's capital targeting behavior is the transfer rule.

\section{Policy rules}

In this section, linear policy rules are introduced in order to specify the policy behaviors. First, monetary policy follows the simple Taylor rule. That is, the central bank sets the riskfree gross interest rate (policy interest rate) in response to contemporary inflation as follows:

$$
\begin{gathered}
R_{t}=\alpha_{0}+\alpha \pi_{t}+\theta_{t}, \\
\theta_{t}=\rho_{\theta} \theta_{t-1}+\varepsilon_{\theta t},\left(0 \leq \rho_{\theta}<1\right),
\end{gathered}
$$

where $\alpha_{0}$ and $\alpha$ are policy parameters, $\theta_{t}$ refers to the monetary policy shock which follows the $\operatorname{AR}(1)$ process and $\varepsilon_{\theta t}$ is white noise. Note that the central bank does not adjust the policy interest rate in response to its capital level. In other words, the model central bank does not try to target its capital by printing money.

Second, the fiscal authority determines the transfer to the central bank by following the next rule.

$$
\begin{gathered}
\kappa_{t}=\kappa_{0}+\gamma_{Q}\left(\overline{c a p}-b_{t-1}^{C}+m_{t-1}\right)+\xi_{t,} \\
\xi_{t}=\rho_{\xi} \xi_{t-1}+\varepsilon_{\xi t},\left(0 \leq \rho_{\xi}<1\right),
\end{gathered}
$$

where $\kappa_{0}$ and $\gamma_{Q}$ are policy parameters, $\xi_{t}$ is the AR(1) random policy shock, $b_{t-1}^{C}-m_{t-1}\left(\equiv B_{t-1}^{C} / P_{t-1}-M_{t-1} / P_{t-1}\right)$ is the real capital of the central bank, $\overline{c a p}$ is the central bank's real capital target and $\varepsilon_{\xi t}$ is white noise. The quasi-fiscal policy rule (24) states that the transfer between the central bank and the fiscal authority may or may not be responsive to the level of the central bank's real capital. When the central bank's real capital falls below the target level ( $\overline{c a p}$ ), the fiscal authority's transfer to the central bank increases if the parameter $\gamma_{Q}$ is strictly positive. If the parameter $\gamma_{Q}$ is zero, then the fiscal authority does not adjust its transfer to the central bank in response to the level of the central bank's capital. The quasi-fiscal policy shock $\xi_{t}$ is the random part of the transfer. The following sections of 
this paper show that the central bank's earning shock may affect inflation when $\gamma_{Q}$ is sufficiently small.

One may argue against the practical relevance of the transfer rule by assuming that $\kappa_{t}$ always stabilizes the central bank's capital in practice. It is generally true that central banks remit their positive net profit to fiscal authorities, while maintaining a certain level of capital. However, in contradictory cases where the central bank has a negative net profit, the remittance from the fiscal authority to the central bank is not guaranteed. The asymmetry in the disposal of profits and losses is ubiquitous for the central banks around the world including the Federal Reserve System of the United States (Stella and Lönnberg, 2008). Even if the transfer $\left(\kappa_{t}\right)$ becomes irresponsive to the central bank capital only temporarily, the quasi-fiscal policy rule still may affect equilibrium. Chung, Davig, and Leeper (2007) showed that features of the other policy regime can be embedded into the equilibrium of the current regime through the agent's expectation in an environment where policy is switching between regimes.

Finally, the fiscal authority determines fiscal surplus $s_{t}$ by the rule (25). Given this rule, the fiscal surplus may or may not be constrained by the level of the fiscal authority's debt.

$$
\begin{gathered}
s_{t}=\gamma_{0}+\gamma_{F} b_{t-1}^{A}+\psi_{t}, \\
\psi_{t}=\rho_{\psi} \psi_{t-1}+\varepsilon_{\psi t},\left(0 \leq \rho_{\psi}<1\right),
\end{gathered}
$$

where $\gamma_{0}$ and $\gamma_{F}$ are the policy parameters, $b_{t}^{A}$ is the real value of the fiscal authority's debt held by the agent $\left(B_{t}^{A} / P_{t}\right), \psi_{t}$ is an $\operatorname{AR}(1)$ fiscal policy shock and $\varepsilon_{\psi t}$ is white noise.

\section{Equilibrium}

The rational-expectations general equilibrium is defined as the sequence of price $\left\{P_{t}\right\}$, the sequences of policy variables $\left\{R_{t}, s_{t}, \kappa_{t}\right\}$, and the sequences of allocations $\left\{c_{t}, M_{t}, M_{t}^{s}, B_{t}^{A}, B_{t}^{C}, B_{t}^{s}\right\}$. The sequences satisfy equilibrium conditions ((9) and (10)), the market clearing conditions $((6),(7)$ and (8)), the public sector budget constraints $((12)$ and (13)) and the policy rules $\left((23),(24)\right.$ and (25)), given the exogenous processes $\left\{y_{t}, \theta_{t}, \xi_{t}, \psi_{t}\right\}$. In addition, the optimal condition (5) and the assumptions ((17) and (18)) are satisfied in the equilibrium.

This paper focuses on the equilibrium in which the central bank's net liability valuation formula (19) uniquely determines the price level. Similar to Cochrane's (2001) characterization of the fiscal theory of the price level, the price level is determined by the ratio of the central bank's net liability to the present value of the central bank's future earnings in such equilibrium. The complete characterization of the policy regime in which 
such equilibrium is realized will be explored in Section III within the context of a linearized system.

\section{LINEARIZED SYSTEM}

In this section, the equilibrium conditions are linearized around the deterministic steady state while the equilibrium conditions are expressed in exact nonlinear forms in Section II. Specifically, this section's analysis is restricted to the equilibria with the bounded inflation rate and real values of bonds $\left(b_{t}^{A}\right.$ and $\left.b_{t}^{C}\right) .{ }^{11}$ In addition, this section assumes the log utility function and a constant output for simplicity.

$$
u\left(c_{t}\right)=\log c_{t}, v\left(\frac{M_{t}}{P_{t}}\right)=\chi \log \frac{M_{t}}{P_{t}}, y_{t}=y, \forall t,
$$

where $\chi$ is a parameter for the marginal rate of substitution between consumption and the real money balance. In this simple case, the equilibrium conditions from the private agent's behavior ((9) and (10)) become the next two equations.

$$
\begin{aligned}
& \frac{M_{t}}{P_{t}}=\chi y \frac{R_{t}}{R_{t}-1}, \\
& \frac{1}{R_{t}}=\beta E_{t}\left[\frac{1}{\pi_{t+1}}\right],
\end{aligned}
$$

where the inflation rate $\pi_{t+1} \equiv P_{t+1} / P_{t}$. Another notable simplification from the log-utility and constant output assumption is that the seigniorage and real pricing kernel are constant for each period.

$$
\begin{gathered}
\frac{i_{t}}{1+i_{t}} f\left(y_{t}, i_{t}\right)=\chi y, \\
X_{t, t+1}=\beta, \forall t .
\end{gathered}
$$

\footnotetext{
${ }^{11}$ If we restrict the analysis to the equilibria with the bounded inflation, then the real values of bonds should also be bounded owing to the assumptions of Proposition 1 .
} 


\section{A. Policy Interactions}

The linear dynamic system is derived from the equilibrium conditions of the private agents' optimization ((27) and (28)), the policy rules ((23), (24), and (25)) and the public sector's flow budget constraints ((12) and (13)), after they have been linearized. In order to apply Sims's (2001) algorithm, the system is summarized in a matrix form as follows.

$$
\Gamma_{0} x_{t+1}=\Gamma_{1} x_{t}+\Phi_{0} z_{t+1}+\Phi_{1} z_{t}+\Pi_{t+1}
$$

where the vector of the endogenous variables is $x_{t} \equiv\left(\hat{\pi}_{t}, \hat{b}_{t}^{C}, \hat{b}_{t}^{A}\right)^{\prime}$, the vector of the exogenous shocks is $z_{t} \equiv\left(\theta_{t}, \xi_{t}, \psi_{t}\right)^{\prime}$, the forecast error vector is $\Pi_{t+1} \equiv\left(\eta_{t+1}, 0,0\right)^{\prime}$, $\eta_{t+1} \equiv \pi_{t+1}-E_{t}\left[\pi_{t+1}\right], \Gamma$ and $\Phi$ are $3 \times 3$ parameter matrices, and the ${ }^{\wedge}$ notation is used for the linear deviation from the deterministic steady state.

Proposition 2. Three regions of policy parameter space (regimes) deliver unique stationary solutions of the system (31).

Proof. In order to uniquely determine the system's (31) solution, only one of eigenvalues of the transition matrix $\Gamma_{0}^{-1} \Gamma_{1}$ should be greater than one in absolute value because only one endogenous forecast error $\left(\eta_{t+1}\right)$ exists in the system. ${ }^{12}$ The three eigenvalues are as follows:

$$
\alpha \beta, \beta^{-1}-\gamma_{Q}, \beta^{-1}-\gamma_{F}
$$

That is, the existence and uniqueness of the solution depends upon the policy parameters ( $\alpha$, $\gamma_{Q}$ and $\gamma_{F}$ ) and the deep behavioral parameter $(\beta)$. In addition, each policy parameter has one associated eigenvalue within the system. If an active policy is defined as the policy for which the associated eigenvalue is unstable, then it is obvious that only one of the three policies should be active in order for the system to have a unique solution. The three policy regimes that determine unique equilibria are as follows.

$$
\begin{array}{cl}
\text { AMP regime: } & |\alpha \beta|>1,\left|\beta^{-1}-\gamma_{Q}\right|<1,\left|\beta^{-1}-\gamma_{F}\right|<1, \\
\text { AQFP regime: } & |\alpha \beta|<1,\left|\beta^{-1}-\gamma_{Q}\right|>1,\left|\beta^{-1}-\gamma_{F}\right|<1, \\
\text { AFP regime: } & |\alpha \beta|<1,\left|\beta^{-1}-\gamma_{Q}\right|<1,\left|\beta^{-1}-\gamma_{F}\right|>1 .
\end{array}
$$

The active monetary policy (AMP) and active fiscal policy (AFP) regimes are well-known policy regimes. In the AMP regime, the monetary policy actively sets the policy interest rate in order to stabilize inflation, while passive fiscal policy supports the real value of the fiscal

\footnotetext{
12 The detailed derivation of the solution is described in Appendix II.
} 
authority's liability. In the AFP regime, the expected path of the fiscal surplus determines inflation, while the monetary policy passively accommodates the determined inflation path by adjusting the nominal money balance. A novel finding of this paper is the equilibrium in the active quasi-fiscal policy (AQFP) regime and the requirements for the passive quasifiscal policy when other policies are active. In the AQFP regime, the active quasi-fiscal policy determines inflation, and other policies are passive in the same way as in the other regimes. When the quasi-fiscal policy is passive, it tries to support the real value of the public sector liability.

A brief intuition of this policy interaction can be found in the following equilibrium conditions.

$$
\begin{gathered}
E_{t}\left[\hat{\pi}_{t+1}\right]=\alpha \beta \hat{\pi}_{t}+\beta \hat{\theta}_{t}, \\
\frac{-\left(m-R b^{C}\right)}{\pi^{2}} \hat{\pi}_{t}=\sum_{T=t}^{\infty} E_{t}\left[\beta^{T-t}\left(\chi y+\hat{\kappa}_{T}\right)\right] \\
\frac{-\left(R b^{C}+R b^{A}\right)}{\pi^{2}} \hat{\pi}_{t}=\sum_{T=t}^{\infty} E_{t}\left[\beta^{T-t}\left(\hat{s}_{T}-\hat{\kappa}_{T}\right)\right]
\end{gathered}
$$

where (32) is the linearized Fisher equation after substituting the monetary policy rule and $m, R, b^{C}, b^{A}$ and $\pi$ are the steady state values. Equations (33) and (34) are simplifications of the IECs (19) and (20) using Equations (29) and (30). ${ }^{13}$

First, if monetary policy is active $(|\alpha \beta|>1)$, the expectational difference equation (32) can be utilized to determine $\pi_{t}$. In this case, for the existence and uniqueness of the solution, the transfer $\left\{\kappa_{T}\right\}$ should support the real value of the central bank's liability (left side of IEC (33)) by being endogenously determined through the IEC (33). Meanwhile, the fiscal surplus $\left\{s_{T}\right\}$ should be passively adjusted in order to support the real value of the fiscal authority's liability in the IEC (34).

Second, active quasi-fiscal policy $\left(\left|\beta^{-1}-\gamma_{Q}\right|>1\right)$ implies that the transfer $\left\{\kappa_{T}\right\}$ is not responsive to the state of the central bank's capital. Then, $\left\{\kappa_{T}\right\}$ can be regarded as an exogenous process in the IEC (33). Therefore, the IEC (33) imposes a restriction on inflation since all variables other than inflation are predetermined or exogenous. The passive monetary policy in Equation (32) $(|\alpha \beta|<1)$ means that the expectational difference equation (32) does

\footnotetext{
${ }^{13}$ The IECs (33) and (34) are derived by linearizing the IECs (19) and (20) around the steady state by assuming that the economy was in the steady state at period $t-1$.
} 
not restrict inflation $\pi_{t}$. Again, the passive fiscal policy supports the real value of the fiscal authority's liability so that the IEC (34) does not bind inflation.

Third, when the fiscal policy is active, the monetary and quasi-fiscal policies should be passive. Specifically, Equation (32) should not impose an additional restriction on inflation and the transfer $\left\{\kappa_{T}\right\}$ should be passive in a way that it is endogenously determined by the IECs (33) and (34), simultaneously. Since the endogenous process $\left\{\kappa_{T}\right\}$ appears in both the IECs, the two IECs jointly determine inflation. In other words, the unified IEC (14) is the single equation to be imposed on the inflation process. Note that this equilibrium is the same as in the fiscal theory of the price level.

A notable feature of the policy interaction is that passive monetary policy does not need to raise the seigniorage revenue in order to cover the decreased transfer from the fiscal authority or the decreased fiscal authority surplus. The real seigniorage revenue is even a fixed number $(\chi y)$ for all of the periods in this model. Even if the seigniorage is a function of the nominal interest rate under general circumstances, it is still the case that the nominal interest rate is not responsive to inflation when monetary policy is passive. Therefore, in this case, the present value of the seigniorage in the IEC (33) can be treated as a fixed number. In sum, it is a misleading statement that passive monetary policy raises the seigniorage in order to balance the intertemporal budgets. Instead, the passive central bank adjusts the nominal money balance in order to accommodate the real money market clearing condition (9) in accordance with the equilibrium price level, which is determined elsewhere.

\section{B. Equilibrium in the Active Quasi-Fiscal Policy Regime}

As discussed in Proposition 2, if the quasi-fiscal policy is active while the monetary and fiscal policies are passive, then a unique stationary equilibrium inflation path exists. The nature of this equilibrium is different from that of AMP and AFP regimes as the quasi-fiscal policy shock affects surprise inflation and the direction of the effect depends upon the steady state value of the central bank's capital. ${ }^{14}$ For a simple illustration, the following special case is considered:

$$
\alpha, \gamma_{Q}, \rho_{\theta}, \rho_{\xi}, \rho_{\psi}=0,\left|\beta^{-1}-\gamma_{F}\right|<1
$$

The central bank pegs the policy interest rate $(\alpha=0)$, the fiscal authority's transfer to the central bank is not responsive to the level of the central bank's capital ( $\left.\gamma_{Q}=0\right)$, the policy shocks are independent and identically distributed (i.i.d.) and the fiscal authority sufficiently adjusts the lump-sum tax in response to the level of its own debt held by the agent. In this

\footnotetext{
${ }^{14}$ Equilibria in AMP and AFP regimes are fundamentally the same as in conventional models, such as in Leeper (1991). Thus, those equilibria are not discussed in this paper.
} 
case, surprise inflation is a function of the innovation in the quasi-fiscal policy (shock in the transfer, $\left.\varepsilon_{\xi t}\right)$.

$$
\eta_{t}=\frac{\pi^{2}}{R b^{C}-m} \varepsilon_{\xi t}
$$

where $R$ is the steady state value of the gross interest rate, $b^{C}$ is the steady state real value of the central bank's holding of the fiscal authority bonds, $m$ is the steady state value of the real money balance and $R b^{C}-m$ is the steady state value of the central bank's real capital. If the benchmark model is extended to include risky assets of the central bank, then the random return shocks from the asset will also affect surprise inflation as shown in Section IV.

Inflation is the sum of the expected inflation and surprise inflation. Since the surprise inflation was solved in Equation (36), inflation is determined as follows in the AQFP regime.

$$
\hat{\pi}_{t}=\beta \varepsilon_{\theta t-1}+\frac{\pi^{2}}{R b^{C}-m} \varepsilon_{\xi t} .
$$

Note that $\beta \varepsilon_{\theta t-1}$ is the expected inflation $E_{t-1}\left[\hat{\pi}_{t}\right]$ in this case. ${ }^{15}$ The solution in Equation (37) implies that the contractionary monetary policy shock (positive $\varepsilon_{\theta t-1}$ ) increases inflation in the next period via the expected inflation. The result is consistent with the simple fiscal theory of the price level (Leeper, 1991) and the 'Unpleasant Monetarist Arithmetic' (Sargent and Wallace, 1981).

The equilibrium inflation in AQFP regime is similar to that of AFP regime, in the sense that the monetary policy shock $\left(\varepsilon_{\theta t}\right)$ does not affect current inflation. Instead of the monetary policy shock, the other policy shocks that alter the value of public sector's liability affect inflation in these cases. The difference between the equilibria in those two policy regimes is the coverage of the public sector liability value which binds equilibria. That is, while the valuation equation for the consolidated government's liability binds equilibrium inflation in AFP regime, the central bank's net liability valuation equation determines equilibrium inflation in AQFP regime.

Analogy between the two regimes is helpful for understanding the economic intuition underlying the equilibrium inflation in both regimes. Figure 1 compares the two cases by illustrating financial portfolio of the three players of the economy (private agent, central bank, and fiscal authority) and flow of resources between the players in return for the assets. For example, the value of the private agent's government bonds holdings $\left(B_{t}^{A}\right)$ is supported by

\footnotetext{
${ }^{15}$ This point can be shown by setting $\alpha=0$ in Equation (32).
} 
the fiscal surplus flows $\left(s_{t}\right)$. The seigniorage $(\chi y)$ and transfer $\left(-\kappa_{t}\right)$ support values of the nominal money balance $\left(M_{t}\right)$ and the central bank's government bonds holdings $\left(B_{t}^{C}\right)$, respectively. Note that the seigniorage is a fixed number in this model for simplicity as shown in Equation (29).

\section{Figure 1. Analogy Diagram of Two Different Policy Regimes}

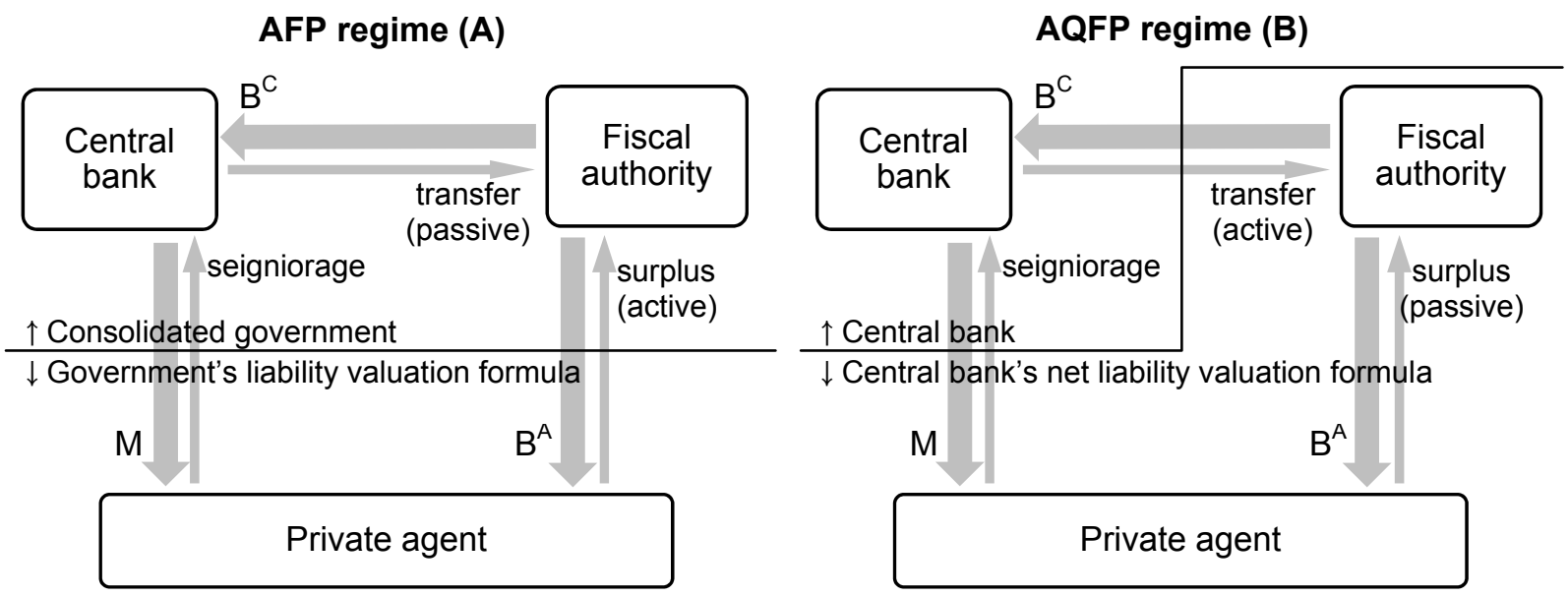

Woodford (2001) and Cochrane (2005) utilized an 'asset pricing analogy' in order to explain economic intuition of the fiscal theory of price level. That is, the private agent's holdings on the consolidated government's liability can be regarded as holdings on shares of the consolidated government. In Cochrane (2005)'s term, the consolidated government's liability ( $M$ and $B^{A}$ ) is a "residual claim to government primary surplus" and seigniorage, "just as Microsoft stock is a residual claim to Microsoft's earnings." As a stock price is determined by the expected present value of its earnings, the price level ${ }^{16}$ is determined by the expected present value of seigniorage and the primary surplus in AFP regime. For example, the unexpected tax cut that is not compensated by future tax hikes makes the agent feel wealthier as 'the stock' price is higher than equilibrium level. Therefore, the private agent tries to adjust his portfolio between consumption and the government's nominal liability, and inflation follows.

Figure 1's panel A shows that, technically, the private agent holds two different stocks (money and government bonds) from two distinct firms (central bank and fiscal authority). However, because the fiscal authority is committed to support the central bank's liability value with the transfer (passive QFP), the private agent is indifferent to the distinction

\footnotetext{
${ }^{16}$ The common price of $M_{t}, B_{t}^{A}$ and $B_{t}^{C}$ in units of consumption goods is $1 / P_{t}$.
} 
between the two firms' stocks. Moreover, the price of the two stock prices are synchronized by a common price $1 / P_{t}$. In the asset pricing analogy's term, the two firms are in effect merged. Therefore, the central bank and the fiscal authority are treated as a unified entity in the conventional fiscal theory of price level.

Panel B shows that such unification between the two entities is no longer valid in an AQFP regime. As one firm (fiscal authority) does not support the value of the other firm (central bank)'s stock and the cash flow between the two firms (transfer) is exogenously given, the stock prices of two firms should be independently determined. However, in an AQFP regime, the private agent understands that the earning of a firm (the fiscal authority) is endogenously adjusted in response to the stock price (the price level) which is determined elsewhere. ${ }^{17}$ Therefore, the valuation equation for the other firm (the central bank's net liability valuation formula) uniquely determines the common stock price.

Suppose that a negative quasi-fiscal policy shock $\left(\xi_{t}<0\right)$ decreases the transfer from the fiscal authority to the central bank $\left(\kappa_{t}\right)$ unexpectedly. Then, a portfolio adjustment will occur on the part of the private agent. However, the direction of the portfolio adjustment depends on the central bank's capital $\left(R b^{C}-m\right)$ at steady state. In the case of negative capital (positive net liability of central bank), the positive net liability value should be supported by present value of seigniorage and the transfer from the fiscal authority. Owing to the shock, the real value of the net liability (left side of Equation (19)) becomes greater than equilibrium level (right side of Equation (19)) if the price level remains the same as the level before the shock. The situation is similar to the tax cut example in an AFP regime and the private agent feels wealthier. Therefore, as the private agent tries to consume more and hold less money, the negative quasi-fiscal policy shock induces inflation in this case. At the equilibrium, the fiscal authority's real debt burden is alleviated and the implicit tax burden on the agent decreases.

Conversely, the negative quasi-fiscal policy shock induces deflation when the steady state capital of the central bank is positive. In order to intuitively describe this case, suppose that the private agent lends to the fiscal authority $\left(B^{A}<0\right)$ in a great amount than the nominal money holdings $\left(-B^{A}-M>0\right)$ in an AFP case (Panel A). Then, the private agent is not (consolidated government's) liability holder but liability issuer. The value of liability to the fiscal authority should be supported by the lump-sum subsidy (from the fiscal authority to the private agent), not the lump-sum tax. A slight modification of consolidated government's liability valuation formula (14) shows this situation as follows.

$$
\frac{-R_{t-1} B_{t-1}^{A}-M_{t-1}}{P_{t}}=\sum_{T=t}^{\infty} E_{t}\left[X_{t, T}\left(s_{T}^{\prime}-\frac{i_{T}}{1+i_{T}} f\left(y_{T}, i_{T}\right)\right)\right],
$$

\footnotetext{
${ }^{17}$ This situation refers to passive fiscal policy behavior.
} 
where $s^{\prime}$ refers to lump-sum subsidy to the private agent. That is, the consolidated government's capital is positive and the capital value is supported by the lump-sum subsidy less seigniorage. If the lump-sum subsidy unexpectedly increases and the general price level remains the same, the private agent finds that the liability value $\left(-B^{A}\right)$ falls below the equilibrium level (right side of (38)). Since the prices of $B^{A}$ and $M$ are synchronized, the private agent tries to consume less and hold more money and deflation follows.

The argument for the positive central bank capital case is similar. The modification of the central bank's net liability valuation formula (19) shows that the central bank's positive capital value is equivalent to the transfer to the fiscal authority less seigniorage as in following equation.

$$
\frac{R_{t-1} B_{t-1}^{C}-M_{t-1}}{P_{t}}=\sum_{T=t}^{\infty} E_{t}\left[X_{t, T}\left(\kappa_{T}^{\prime}-\frac{i_{T}}{1+i_{T}} f\left(y_{T}, i_{T}\right)\right)\right]
$$

where $\kappa^{\prime}$ refers to transfer from the central bank to the fiscal authority. The negative quasifiscal policy shock increases $\kappa^{\prime}$ and the private agent finds that the liability value $\left(B^{C}\right)$ falls below the equilibrium level. The portfolio adjustment between the nominal money balance and consumption induces deflation in the end.

Two more important features of the equilibrium should be noted. First, the model's economic mechanism for inflation does not rely on the central bank's money creation in response to the transfer to the government. In the first step of the adjustment procedure, the central bank fixed the nominal money balance, but inflation (deflation) is still induced by the quasi-fiscal shock. A similar statement can be made for the fiscal theory of the price level. In the active fiscal policy regime, the tax shock does not require the creation of money in order to have an impact on the price level. Otherwise, the tax shock induces the agent's portfolio adjustment, and, thus, the price changes. Therefore, this model's application is never restricted to extreme situations, such as a large scale transfer between two public institutions.

Second, the equilibrium in the AQFP regime is observationally equivalent to the equilibria in the AMP and AFP regimes. Suppose that a quasi-fiscal policy shock causes inflation in the AQFP regime. Then, the nominal money balance must be increased passively in order to clear the money market equilibrium condition (27) and the future fiscal surplus must be passively decreased in accordance with the price change by the fiscal policy rule (25). The required tax change in the present value can be shown by adding (19) to (20). This observational relationship between inflation, the nominal money balance, and the fiscal surplus is the same as in the other regimes, although the causal relationships are opposite. For instance, in the AMP regime, an expansion of the nominal money balance (a negative monetary policy shock) causes inflation and the fiscal surplus is passively decreased. In the AFP regime, the decrease in the fiscal surplus causes inflation and the nominal money balance is passively increased. 


\section{Application to Exit Strategy}

Exit strategy refers to plans to reverse unconventional quasi-fiscal operations, such as credit easing operations, as economic recovery and inflation become imminent. Specifically, the Federal Reserve System will be required to "reduce excess reserve balances" of depository institutions or "neutralize their potential effects on broader measures of money and credit and thus, on aggregate demand and inflation" (Bernanke, 2009). Roughly explained, the exit strategy is the plan to decrease the size of the central bank's balance sheet by selling the assets that have been acquired via unconventional operations.

This section analyzes the exit strategy's potential effects on inflation by extending the benchmark model to include the long-term bonds. Although the primary policy intent of the exit strategy is to avoid high inflation due to large-scale excess liquidity in the economy, this paper explores a different aspect of the strategy. Suppose that the central bank increases the short-term policy interest rate during the implementation of the exit strategy. Since the central bank holds the long-term nominal bonds, an increase in the short-term rate may devaluate the central bank's long-term bond holdings. Then, through a portfolio adjustment of the private agent as seen in Section III, the valuation loss of the central bank may affect inflation in the AQFP regime. The interesting feature of this mechanism is that an increase in the short-term rate (deflationary policy) may lead to inflation when the central bank's capital is negative. In this case, if the real balance demand is stable, then the central bank is driven to a paradoxical situation where it has to increase the nominal money balance to satisfy the money market.

In this extension, the long-term government nominal bonds are introduced. Specifically, $B_{1, t}$ is the face value of one-period nominal bonds issued at $t$ period and $B_{2, t}$ refers to the face value of two-period nominal bonds issued at $t$ period. The short-term bonds $B_{1, t}$ mature at $t+1$ period and are redeemed for the nominal money value $R_{1, t} B_{1, t}$ at $t+1$ period. The long-term bonds $B_{2, t}$ mature at $t+2$ period and are redeemed for the nominal money value $R_{2, t} B_{2, t}$ at maturity. $R_{1, t}$ and $R_{2, t}$ are the gross nominal interest rates for the short- and longterm bonds, respectively.

At $t$ period, let's suppose that the representative agent sells the premature long-term bonds $\left(B_{2, t-1}\right)$ and purchases the new long-term bonds $\left(B_{2, t}\right)$. The premature long-term bonds at

period $t\left(B_{2, t-1}\right)$ are claims for the nominal money value $R_{2, t-1} B_{2, t-1}$ at $t+1$ period. Instead of trading the premature long-term bonds, the private agent has the option to invest in the short-term bonds at $t$ period. Since there should be no arbitrage opportunities, then the two risk-free investment choices (premature long-term bonds and short-term bonds) should have the same return. Therefore, the market price of the premature long-term bonds at $t$ period is $R_{2, t-1} R_{1, t}^{-1}$. 
By including the long-term bonds, the agent's optimization problem is revised as follows:

$$
\max _{\left\{c_{t}, M_{t}, B_{1, t}^{A}, B_{2, t}^{A}\right\}_{t=0}^{\infty}} E_{0}\left[\sum_{t=0}^{\infty} \beta^{t} \log c_{t}+\chi \log \frac{M_{t}}{P_{t}}\right], 0<\beta<1
$$

s.t.

$$
\begin{gathered}
c_{t}+\frac{M_{t}}{P_{t}}+\frac{B_{1, t}^{A}}{P_{t}}+\frac{B_{2, t}^{A}}{P_{t}} \leq y_{t}-\tau_{t}+\frac{M_{t-1}}{P_{t}}+\frac{R_{1, t-1} B_{1, t-1}^{A}}{P_{t}}+\frac{R_{2, t-1} R_{1, t}^{-1} B_{2, t-1}^{A}}{P_{t}}, \\
c_{t}, M_{t} \geq 0, \forall t \geq 0, M_{-1}+R_{1,-1} B_{1,-1}^{A}+R_{2,-1} R_{1,0}^{-1} B_{2,-1}^{A}>0
\end{gathered}
$$

where $B_{\bullet, t}^{A}$ refers to the agent's holdings of the short- and long-term bonds. If the constant output assumption is maintained as seen in Section III, then the Euler equations are Equations (27), (28) ${ }^{18}$ and the following additional equation:

$$
\frac{1}{R_{2, t}}=E_{t}\left[\beta^{2} \frac{P_{t}}{P_{t+2}}\right]=\frac{1}{R_{1, t}} E_{t}\left[\frac{1}{R_{1, t+1}}\right]+\operatorname{COV}\left[\frac{\beta}{\pi_{t+1}}, \frac{\beta}{\pi_{t+2}}\right] .
$$

The additional Euler equation (41) implies the expectations theory of the term structure of interest rates. In regard to the market clearing condition, the bonds market clearing condition is revised as follows, while the money and goods market clearing conditions remain the same as in the previous sections.

$$
\begin{aligned}
& B_{1, t}^{s}=B_{1, t}^{A}+B_{1, t}^{C}, \\
& B_{2, t}^{s}=B_{2, t}^{A}+B_{2, t}^{C},
\end{aligned}
$$

where $B_{\cdot, t}^{s}$ refers to the short- and long-term bond supplies and $B_{\bullet, t}^{C}$ is the central bank's demand for the bonds. ${ }^{19}$

The public sector model should also be extended. First, the central bank holds the long-term government bonds, while the fiscal authority issues the long-term bonds. Parallel to the agent's case, the central bank sells the premature long-term bonds in the market and purchases the newly issued long-term bonds. Then, the flow budget constraints of the central bank and the fiscal authority are as follows:

\footnotetext{
${ }^{18}$ Since the short-term gross interest rate was denoted by $R_{t}$ in the previous sections, $R_{t}$ is equivalent to $R_{1, t}$ in this section.

${ }^{19}$ In addition, the definition of the agent's real financial wealth should be revised to include the long-term bonds.
} 


$$
\begin{gathered}
\frac{B_{1, t}^{C}-R_{1, t-1} B_{1, t-1}^{C}}{P_{t}}+\frac{B_{2, t}^{C}-R_{2, t-1} R_{1, t}^{-1} B_{2, t-1}^{C}}{P_{t}}=\frac{M_{t}-M_{t-1}}{P_{t}}+\kappa_{t}, \\
0=\frac{B_{1, t}-R_{1, t-1} B_{1, t-1}}{P_{t}}+\frac{B_{2, t}-R_{2, t-1} R_{1, t}^{-1} B_{2, t-1}}{P_{t}}+s_{t}-\kappa_{t} .
\end{gathered}
$$

The quasi-fiscal policy rule (24) and the fiscal policy rule (25) should be revised with longterm bonds. The revised rules are:

$$
\begin{gathered}
\kappa_{t}=\kappa_{0}+\gamma_{Q}\left(\overline{c a p}-b_{1, t-1}^{C}-b_{2, t-1}^{C}+m_{t-1}\right)+\xi_{t}, \\
s_{t}=\gamma_{0}+\gamma_{F}\left(b_{1, t-1}^{A}+b_{2, t-1}^{A}\right)+\psi_{t} .
\end{gathered}
$$

Second, the fiscal authority and central bank decide the maturity structure of their liabilities and assets. Cochrane (2001) showed that the maturity structure of the government nominal debt affects the equilibrium price level sequence. In this model extension, the following maturity structure is suggested:

$$
\begin{gathered}
B_{2, t}=\delta B_{1, t},(\delta \geq 0), \\
B_{2, t}^{C}=\left(\delta+\mu_{t}\right) B_{1, t}^{C}, \\
\mu_{t}=\rho_{\mu} \mu_{t-1}+\varepsilon_{\mu t},\left(0 \leq \rho_{\mu}<1\right),
\end{gathered}
$$

where $\delta$ is a policy parameter, $\varepsilon_{\mu t}$ is white noise, and $\mu_{t}$ stands for the $\operatorname{AR}(1)$ exogenous policy shock that affects the central bank's asset maturity structure. In this specification of the maturity structure, the fiscal authority maintains a fixed ratio $(\delta)$ between the face values of the short- and long-term bonds. The central bank maintains the same ratio $(\delta)^{20}$ for its assets in the steady state, while the bank's asset maturity structure deviates from the fixed ratio $(\delta)$ when the policy shock $\mu_{t}$ exists.

The aforementioned maturity policy is such that the central bank (the fiscal authority) adjusts the short- and long-term assets (debts) that are outstanding at each time period. Conversely, in Cochrane's (2001) cases with the outstanding long-term bonds, it was assumed that trade and redemption of premature long-term bonds were not allowed. Since this model allows such transactions, the total face value of the outstanding assets is exposed to the valuation risk when the central bank adjusts its asset balances. That is, if the current short-term interest

\footnotetext{
${ }^{20}$ The basic results of the model remain the same when the fiscal authority's debt maturity ratio is different from the asset maturity ratio of the central bank.
} 
rate $\left(R_{1, t}\right)$ increases, then the value of the premature long-term bonds decreases through the decreased market price $\left(R_{2, t-1} R_{1, t}^{-1}\right)$.

This set-up is appropriate for analyzing issues of the exit strategy. When economic recovery and inflation are imminent, the Federal Reserve System may try to withdraw liquidity from the economy by selling its assets. During that process, it is plausible that the Federal Reserve System will be required to sell premature long-term bonds because a significant portion of the system's assets is contained within long-term bonds. Since the exit strategy increases the short-term interest rate, the valuation loss from trading the premature long-term bonds is relevant in the exit strategy.

By following the same steps as seen in Section III, a linearized dynamic system is constructed for the vector of the endogenous variables $\left(\hat{\pi}_{t}, \hat{b}_{1, t}^{C}, \hat{b}_{1, t}^{A}\right)^{\prime}$. If the policy parameter is a special case of the AQFP regime as seen in Condition (35), then the surprise inflation is

$$
\eta_{t}=\frac{\pi^{2}}{(1+\delta) R_{1} b_{1}^{C}-m}\left(\varepsilon_{\xi t}-\frac{\delta b_{1}^{C}}{\pi} \varepsilon_{\theta t}\right),
$$

where $b_{1}^{C}$ is the steady state value (real) of the central bank's holdings for the short-term bonds. Note that the solution (50) is equivalent to the solution in Section III (36) when no long-term bonds are outstanding $(\delta=0)$.

The results show that when the central bank's steady state capital level is negative $\left((1+\delta) R_{1} b_{1}^{C}-m<0\right)$, then the positive monetary policy shock $\left(\varepsilon_{\theta t}>0\right)$ induces inflation $\left(\eta_{t}>0\right)$ in the AQFP regime. This case is a situation where the central bank already lost significantly from risky assets and the fiscal authority has not been compensating the losses. Since the central bank's asset return is negatively related with the short-term policy interest rate, the positive monetary policy shock has a negative effect on the value of the central bank's net liability. Then, the private agent tries to consume more and hold less nominal money as it is shown in Section III, and surprise inflation follows.

The crucial feature of this scenario is that the central bank without fiscal supports cannot play an active role in stabilizing inflation. As the negative return shock of the central bank induces inflation in this case, the central bank is forced to passively increase the nominal money balance in order to satisfy the money market clearing condition. The initial policy intention of increasing the short-term interest rate is to shrink the central bank's balance sheet and to mitigate inflation, but the central bank's balance sheet inflates even greater in the end. The obvious solution to avoid such a paradoxical result is to systematically recapitalize the central bank by the fiscal authority.

Jeanne and Svensson (2007) pointed out that the negative capital of the central bank may undermine the bank's independence from the fiscal authority. However, it is also true that the central bank can still operate with negative capital. The results of this section show that negative capital may not be desirable to the central banks, but for a different reason. That is, 
a tightening monetary policy shock may ignite further inflation when the capital is negative in a certain policy regime. Although our reasoning is different, our analytic results support Goodfriend's (2011) suggestion. That is, this paper shows that the quasi-fiscal shocks affect inflation when the fiscal authority does not offset the shocks by targeting the central bank's capital. Therefore, policy coordination between the two institutions is indispensable for price stability.

\section{Conclusion}

Conventional macroeconomic models treat the central bank's balance sheet as superficial information that does not affect the equilibrium. However, this paper shows that quasi-fiscal policies, which alter the central bank's balance sheet, affect the equilibrium inflation in a certain policy regime. In the active quasi-fiscal policy regime, the transfer rule between the fiscal authority and central bank does not automatically stabilize the central bank's real capital while monetary and fiscal policies are passive. In this policy regime, the quasi-fiscal shocks, including the losses incurred from the asset holdings, affect inflation via the private agent's portfolio adjustment. Previous studies, which have not considered this possibility, implicitly assume that the quasi-fiscal policy is always passive. However, in general circumstances, the policy's passivity is not guaranteed. In other words, it can be an illusionary belief that the fiscal authority will always automatically support the central bank's losses considering the actual laws on the central banks.

The crucial assumption needed for these results is that the real value of central banks' net liability has a finite upper bound, which is the present value of seigniorage and transfer earnings. This paper also shows that the condition is satisfied under general circumstances. When the condition is satisfied, an additional equilibrium condition exists, which is referred to as the central bank's net liability valuation formula, and the formula may or may not restrict inflation process depending on the activeness of quasi-fiscal policy.

The economic mechanism underlying the equilibrium in the active quasi-fiscal policy regime is the private agent's response to the quasi-fiscal shocks. When a shock occurs to the central bank's returns in this policy regime, the agent tries to adjust her portfolio between the central bank's liability and consumption, thus the shock affects inflation. This mechanism is comparable to the asset pricing relationships, which equate the value of an asset with the present value of the asset's current and future earnings. That is, the central bank's net liability valuation formula is an asset pricing equation where the general price level is the price of the bank's liability with respect to consumption.

By extending the benchmark model, this paper shows that the issues of an exit strategy may affect inflation in undesirable ways. If the policy regime is active quasi-fiscal policy during the implementation of the exit strategy, then the monetary policy shock may affect inflation through the central bank's net liability valuation formula. Notably, the contractionary monetary policy shock induces inflation when the central bank's capital is negative and the central bank cannot successfully unwind unconventional balance sheet. Therefore, the fiscal authority and central bank should coordinate, by stabilizing the central bank's capital, in order to isolate the perverse effects of quasi-fiscal shocks on inflation. 


\section{APPENDIX I. PARt Of The Proof for Proposition 1}

Conditions (15) and (16) imply that Conditions (17) and (18) hold. By summing the flow budget constraints (12) and (13) over the period from $t$ to $T-1$ after taking the discounted expected value (at period $t$ ) of the constraints, the following equations are true for all $T \geq t+1$.

$$
\begin{gathered}
E_{t}\left[X_{t, T} d_{T}^{C}\right]=d_{t}^{C}-\sum_{s=t}^{T-1} E_{t}\left[X_{t, s}\left(\frac{i_{s}}{1+i_{s}} f\left(y_{s}, i_{s}\right)+\kappa_{s}\right)\right], \\
E_{t}\left[X_{t, T} d_{T}^{F}\right]=d_{t}^{F}-\sum_{s=t}^{T-1} E_{t}\left[X_{t, s}\left(s_{s}-\kappa_{s}\right)\right] .
\end{gathered}
$$

From Conditions (15) and (16),

$$
\begin{gathered}
d_{t}^{C}-\sum_{s=t}^{\infty} E_{t}\left[X_{t, s}\left(\frac{i_{s}}{1+i_{s}} f\left(y_{s}, i_{s}\right)+\kappa_{s}\right)\right] \leq 0, \\
d_{t}^{F}-\sum_{s=t}^{\infty} E_{t}\left[X_{t, s}\left(s_{s}-\kappa_{s}\right)\right] \leq 0 .
\end{gathered}
$$

As $T \rightarrow \infty$ in (A1) and (A2),

$$
\begin{gathered}
\lim _{T \rightarrow \infty} E_{t}\left[X_{t, T} d_{T}^{C}\right]=d_{t}^{C}-\sum_{s=t}^{\infty} E_{t}\left[X_{t, s}\left(\frac{i_{s}}{1+i_{s}} f\left(y_{s}, i_{s}\right)+\kappa_{s}\right)\right], \\
\lim _{T \rightarrow \infty} E_{t}\left[X_{t, T} d_{T}^{F}\right]=d_{t}^{F}-\sum_{s=t}^{\infty} E_{t}\left[X_{t, s}\left(s_{s}-\kappa_{s}\right)\right]
\end{gathered}
$$

Equations (A3)-(A6) imply

$$
\begin{aligned}
& -\infty<\lim _{T \rightarrow \infty} E_{t}\left[X_{t, T} d_{T}^{C}\right] \leq 0, \\
& -\infty<\lim _{T \rightarrow \infty} E_{t}\left[X_{t, T} d_{T}^{F}\right] \leq 0 .
\end{aligned}
$$

since $\left|w_{t}^{A}\right|<\infty$ and the Conditions (15) and (16) imply $d_{t}^{C}, d_{t}^{F}>-\infty$. Owing to the agent's transversality condition (5),

$$
\lim _{T \rightarrow \infty} E_{t}\left[X_{t, T} d_{T}^{C}\right]+\lim _{T \rightarrow \infty} E_{t}\left[X_{t, T} d_{T}^{F}\right]=0
$$


since $w_{T}^{A}=d_{T}^{C}+d_{T}^{F}$. Therefore,

$$
\begin{aligned}
& \lim _{T \rightarrow \infty} E_{t}\left[X_{t, T} d_{T}^{C}\right]=0, \\
& \lim _{T \rightarrow \infty} E_{t}\left[X_{t, T} d_{T}^{F}\right]=0 .
\end{aligned}
$$

Conversely, Conditions (A10) and (A11) imply that assumptions (15) and (16) hold. Suppose that Conditions (A10) and (A11) are true. From the budget constraints, Equations (A1) and (A2) are true. As $T \rightarrow \infty$ in Equations (A1) and (A2), Conditions (A3) and (A4) hold by equality. Then, since $d_{t}^{C}$ and $d_{t}^{F}$ are finite, Conditions (15) and (16) are necessarily true. Therefore, Conditions (15) and (16) are equivalent to Conditions (A10) and (A11). 


\section{APPENDIX II. SOLUTION OF THE DYNAMIC SYSTEM IN SECTION III}

In order to arrange the model with a linear dynamic system, this paper linearizes the Fisher equation (28) and the budget constraints ((12) and (13)). These three equations form a dynamic system in matrix equation (A12). The first row of (A12) is from the Fisher equation, the second row is from the central bank budget constraint and the third row is from the fiscal authority budget constraint. The money market equilibrium condition (27) and the policy rules $((23),(24)$ and (25)) are substituted into the three equations. In the coefficient matrices $\left(\Gamma_{0}, \Gamma_{1}, \Phi_{0}\right.$ and $\left.\Phi_{1}\right)$, the variables without time index refer to the steady state values.

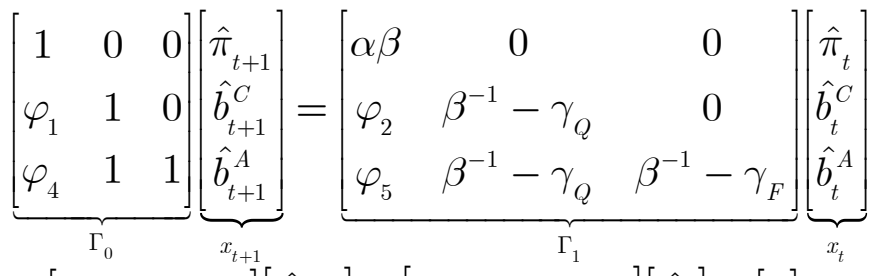

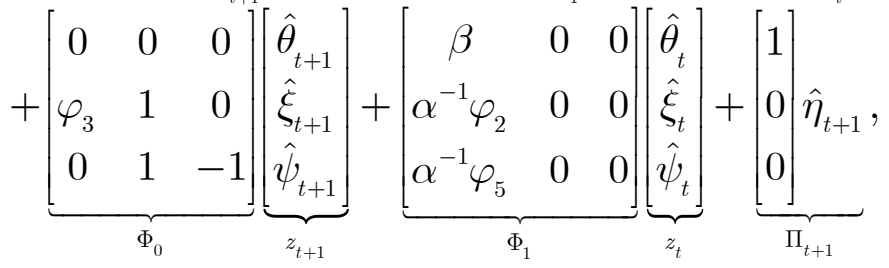

where

$$
\varphi_{1} \equiv \frac{R b^{C}-m}{\pi^{2}}+\frac{\alpha \chi y}{(R-1)^{2}}, \varphi_{2} \equiv \frac{\alpha}{\pi}\left[\frac{\chi y}{(R-1)^{2}}+b^{C}\right]-\frac{\alpha \gamma_{Q} \chi y}{(R-1)^{2}}, \varphi_{3} \equiv \frac{-\chi y}{(R-1)^{2}},
$$

$$
\varphi_{4} \equiv \frac{R b^{A}+R b^{C}}{\pi^{2}}, \varphi_{5} \equiv \frac{\alpha}{\pi}\left(b^{A}+b^{C}\right)-\frac{\alpha \gamma_{Q} \chi y}{(R-1)^{2}}
$$

If the vectors $x_{t}$ and $z_{t}$ are stacked, then the system (A12) becomes Equation (A13).

$$
\underbrace{\left[\begin{array}{l}
\hat{\pi}_{t+1} \\
\hat{b}_{t+1}^{C} \\
\hat{b}_{t+1}^{A} \\
\hat{\theta}_{t+1} \\
\hat{\xi}_{t+1} \\
\hat{\psi}_{t+1}
\end{array}\right]}_{Y_{t+1}}=\underbrace{\left[\begin{array}{cccccc}
\alpha \beta & 0 & 0 & \beta & 0 & 0 \\
\varphi_{6} & \beta^{-1}-\gamma_{Q} & 0 & \varphi_{7} & \rho_{\xi} & 0 \\
\varphi_{8} & 0 & \beta^{-1}-\gamma_{F} & \varphi_{9} & 0 & -\rho_{\psi} \\
0 & 0 & 0 & \rho_{\theta} & 0 & 0 \\
0 & 0 & 0 & 0 & \rho_{\xi} & 0 \\
0 & 0 & 0 & 0 & 0 & \rho_{\psi}
\end{array}\right]}_{A} \underbrace{\left[\begin{array}{c}
\hat{\pi}_{t} \\
\hat{b}_{t}^{C} \\
\hat{b}_{t}^{A} \\
\hat{\theta}_{t} \\
\hat{\xi}_{t} \\
\hat{\psi}_{t}
\end{array}\right]}_{Y_{t}}+\underbrace{\left[\begin{array}{cccccc}
1 & 0 & 0 & 0 & 0 & 0 \\
-\varphi_{1} & 0 & 0 & \varphi_{3} & 1 & 0 \\
\varphi_{1}-\varphi_{4} & 0 & 0 & -\varphi_{3} & 0 & -1 \\
0 & 0 & 0 & 1 & 0 & 0 \\
0 & 0 & 0 & 0 & 1 & 0 \\
0 & 0 & 0 & 0 & 0 & 1
\end{array}\right]}_{C} \underbrace{\left[\begin{array}{c}
\eta_{t+1} \\
0 \\
0 \\
\varepsilon_{\theta t+1} \\
\varepsilon_{\xi t+1} \\
\varepsilon_{\psi t+1}
\end{array}\right],}_{\zeta_{t}},
$$


where

$$
\begin{aligned}
& \varphi_{6} \equiv \varphi_{2}-\alpha \beta \varphi_{1}, \varphi_{7} \equiv \rho_{\theta} \varphi_{3}-\beta \varphi_{1}+\alpha^{-1} \varphi_{2}, \\
& \varphi_{8} \equiv \alpha \beta\left(\varphi_{1}-\varphi_{4}\right)-\varphi_{2}+\varphi_{5}, \varphi_{9} \equiv-\rho_{\theta} \varphi_{3}+\alpha^{-1} \varphi_{8} .
\end{aligned}
$$

The eigenvalues of transition matrix $A$ can be read off from the diagonal elements. By the eigenvector decomposition, matrix $A$ can be decomposed into $P \Lambda P^{-1}$ where $\Lambda$ is a diagonal matrix with eigenvalues, and the columns of the $P$ matrix are the right eigenvectors of $A . P^{-1}$ can be expressed as matrix (A14).

$$
P^{-1}=\left[\begin{array}{cccccc}
1 & 0 & 0 & \frac{\beta}{\alpha \beta-\rho_{\theta}} & 0 & 0 \\
p_{1} & 1 & 0 & p_{2} & p_{3} & 0 \\
p_{4} & 0 & 1 & p_{5} & 0 & p_{6} \\
0 & 0 & 0 & 1 & 0 & 0 \\
0 & 0 & 0 & 0 & 1 & 0 \\
0 & 0 & 0 & 0 & 0 & 1
\end{array}\right],
$$

where

$$
\begin{aligned}
& p_{1} \equiv \frac{-\varphi_{6}}{\alpha \beta-\beta^{-1}+\gamma_{Q}}, p_{2} \equiv \frac{1}{\beta^{-1}-\gamma_{Q}-\rho_{\theta}}\left(\varphi_{7}-\frac{\beta \varphi_{6}}{\alpha \beta-\beta^{-1}+\gamma_{Q}}\right), p_{3} \equiv \frac{\rho_{\xi}}{\beta^{-1}-\gamma_{Q}-\rho_{\xi}} \\
& p_{4} \equiv \frac{-\varphi_{8}}{\alpha \beta-\beta^{-1}+\gamma_{F}}, p_{5} \equiv \frac{1}{\beta^{-1}-\gamma_{F}-\rho_{\theta}}\left(\varphi_{9}-\frac{\beta \varphi_{8}}{\alpha \beta-\beta^{-1}+\gamma_{F}}\right), p_{6} \equiv \frac{-\rho_{\psi}}{\beta^{-1}-\gamma_{F}-\rho_{\psi}} .
\end{aligned}
$$

The solution of the system is derived by eliminating the explosive eigenvalues. If the $\mathrm{j}$ 'th eigenvalue is explosive, then the solution is such that $P^{j \bullet} Y_{t}=0$ where $P^{j \bullet}$ refers to the j'th row of $P^{-1}$. The linear mappings from the exogenous shock to the endogenous forecast error are given by $P^{j \cdot} C \zeta_{t}=0$. 


\section{REFERENCES}

Bernanke, B.S., 2009, “The Federal Reserve's Balance Sheet: An Update,” (speeches by the Federal Reserve Board Chairman at the Federal Reserve Board Conference on Key Developments in Monetary Policy, October 9.) (Washington, DC: Federal Reserve).

Berriel, T.C., and S. Bhattarai, 2009, "Monetary Policy and Central Bank Balance Sheet Concerns," The B.E. Journal of Macroeconomics 9, Issue 1 (Contributions), Article 1.

Canzoneri, M.B., R.E. Cumby, and B.T. Diba, 2001, "Is the Price Level Determined by the Needs of Fiscal Solvency?" American Economic Review 91(5), 1221-38.

Chung, H., T. Davig, and E.M. Leeper, 2007, "Monetary and Fiscal Policy Switching," Journal of Money, Credit and Banking 39(4), 809-42.

Cochrane, J.H., 2001, "Long-Term Debt and Optimal Policy in the Fiscal Theory of the Price Level," Econometrica 69(1), 69-116.

, 2005, “Money as Stock,” Journal of Monetary Economics 52(3), 501-28.

Goodfriend, M., 2011, "Central Banking in the Credit Turmoil: An Assessment of Federal Reserve Practice," Journal of Monetary Economics 58(1), 1-12.

Goodhart, C.A.E., 1988, The Evolution of Central Banks (Cambridge, Massachusetts: MIT Press).

Jeanne, O., and L.E.O. Svensson, 2007, "Credible Commitment to Optimal Escape from a Liquidity Trap: The Role of the Balance Sheet of an Independent Central Bank," American Economic Review 97(1), 474-90.

Klüh, U., and P. Stella, 2008, "Central Bank Financial Strength and Policy Performance: An Econometric Evaluation,” IMF Working Paper 08/176 (Washington: International Monetary Fund).

Leeper, E.M., 1991, “Equilibria under 'Active' and 'Passive' Monetary and Fiscal Policies," Journal of Monetary Economics 27(1), 129-47.

Mackenzie, G.A., and P. Stella, 1996, "Quasi-Fiscal Operations of Public Financial Institutions," IMF Occasional Paper No. 142 (Washington: International Monetary Fund).

Sargent, T.J., and N. Wallace, 1981, “Some Unpleasant Monetarist Arithmetic,” Federal Reserve Bank of Minneapolis Quarterly Review, 5(Fall), 1-17.

Sims, C.A., 1994, "A Simple Model for Study of the Determination of the Price Level and the Interaction of Monetary and Fiscal Policy," Economic Theory 4(3), 381-99. 
, 2001, "Solving Linear Rational Expectations Models," Journal of Computational Economics 20(1), 1-20. ,2003, "Fiscal Aspects of Central Bank Independence,” Unpublished manuscript, Princeton, New Jersey: Princeton University.

Stella, P., and A. Lönnberg, 2008, "Issues in Central Bank Finance and Independence," IMF Working Paper 08/37 (Washington: International Monetary Fund).

Woodford, M., 2001, "Fiscal Requirements for Price Stability," Journal of Money, Credit and Banking 33(3), 669-728. 